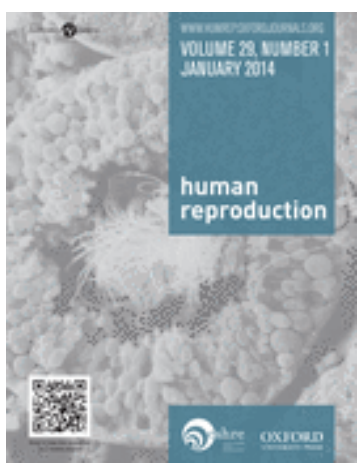

Draft Manuscript For Review. Reviewers should submit their review at http://mc.manuscriptcentral.com/humrep

\title{
Imprinting disorders in children born after assisted reproductive technology (ART): a Nordic study from the CoNARTaS group
}

\begin{tabular}{|r|l|}
\hline Journal: & Human Reproduction \\
\hline Manuscript ID & HUMREP-19-1287.R2 \\
\hline Manuscript Type: & Original Article \\
\hline Author: & n/a \\
\hline Complete List of Authors: & $\begin{array}{l}\text { Henningsen, Anna-Karina; Rigshospitalet, Copenhagen University } \\
\text { Hospital, Fertility Clinic } \\
\text { Gissler, Mika; THL Finnish Institute for Health and Welfare, Information } \\
\text { Services Department; Karolinska Institute, Department of Neurobiology, } \\
\text { Care Sciences and Society, Division of Family Medicine } \\
\text { Rasmussen, Steen; Rigshospitalet, Copenhagen University Hospital, } \\
\text { Fertility Clinic } \\
\text { Opdahl, Signe; Central Norway Regional Health Authority; Norwegian } \\
\text { University of Science and Technology, Department of Public Health and } \\
\text { General Practice } \\
\text { Wennerholm, U B; Institute of Clinical Sciences, Sahlgrenska Academy, } \\
\text { University of Gothenburg, Department of Obstetrics and Gynecology } \\
\text { Spangsmose, Anne Lærke; Rigshospitalet, Copenhagen University } \\
\text { Hospital, Fertility Clinic } \\
\text { Tiitinen, Aila; University of Helsiniki, Helsinki University Hospital, } \\
\text { Department of Obstetrics and Gynecology } \\
\text { Bergh, Christina; Institute of Clinical Sciences, Sahlgrenska Academy, } \\
\text { University of Gothenburg, Department of Obstetrics and Gynecology } \\
\text { Romundstad, Liv Bente; Central Norway Regional Health Authority; } \\
\text { Norwegian University of Science and Technology, Department of Public } \\
\text { Health and General Practice; Spiren Fertility Clinic } \\
\text { Laivuori, Hannele; University of Helsinki, Institute for Molecular Medicine } \\
\text { Finland, Helsinki Institute of Life Science; University of Helsinki, Helsinki } \\
\text { University Hospital, Medical and Clinical Genetics; Faculty of Medicine } \\
\text { and Health Technology, University of Tampere, Tampere University } \\
\text { Hospital, Department of Obstetrics and Gynecology } \\
\text { Forman, Julie; University of Copenhagen, Department of Biostatistics } \\
\text { Pinborg, Anja; Rigshospitalet, Copenhagen University Hospital, Fertility } \\
\text { Clinic }\end{array}$ \\
\hline
\end{tabular}




\begin{tabular}{|r|l|}
\hline & $\begin{array}{l}\text { Lidegaard, Øjvind; Rigshospitalet, Copenhagen University Hospital, } \\
\text { Gynecological Clinic }\end{array}$ \\
\hline Keywords: & $\begin{array}{l}\text { ASSISTED REPRODUCTION, CHILD FOLLOW-UP, IMPRINTING, IVF/ICSI } \\
\text { OUTCOME, EPIDEMIOLOGY }\end{array}$ \\
\hline Subject Section: & Reproductive Epidemiology \\
\hline \multicolumn{2}{|l}{} \\
\hline
\end{tabular}

SCHOLARONE $^{\text {IM }}$ Manuscripts 


\section{Abstract}

Study question: Is the risk of imprinting disorders increased in children conceived after assisted reproductive technology (ART)?

Summary answer: We found an adjusted odds ratio of $2.84[95 \% \mathrm{Cl} 1.34-6.01]$ for BeckwithWiedemann syndrome in ART children, while the risk of Prader-Willi syndrome, Silver-Russell syndrome or Angelman syndrome was not increased in children conceived after ART.

What is known already: Earlier studies, most of them small, have suggested an association between ART and imprinting disorders.

Study design, size, duration: Binational register-based cohort study. All children conceived by ART in Denmark ( $n=45$ 393) born between1994 and 2014 and in Finland $(n=29244)$ born between 1990 and 2014 were identified. The full background populations born during the same time periods in the two countries were included as controls. Odds ratios of imprinting disorders in ART children compared with naturally conceived (NC) children were calculated. The median follow-up time was 8 years and 9 months for ART children and 11 years and 9 months for NC children.

Participants/materials, setting, methods: From the national health registries in Denmark and Finland, we identified all children diagnosed with Prader-Willi syndrome $(n=143)$; Silver-Russell syndrome $(n=69)$; Beckwith-Wiedemann syndrome $(n=105)$ and Angelman syndrome $(n=72)$ born between 1990/1994 and 2014, respectively.

Main results and the role of chance: We identified a total of 388 children diagnosed with imprinting disorders, sixteen of these were conceived after ART. The overall adjusted odds ratio for the four imprinting disorders in ART children compared with NC children was $1.35[95 \% \mathrm{Cl} 0.80-$ 2.29], but since eight ART children were diagnosed with Beckwith-Wiedemann syndrome, the adjusted odds ratio for this specific imprinting disorder was $2.84[95 \% \mathrm{Cl} 1.34-6.01]$. The absolute risk of Beckwith-Wiedemann syndrome was still low: 10.7 out of 100000 newborns. The risk of 
25 Prader-Willi syndrome, Silver-Russell syndrome and Angelman syndrome was not increased in 26 children conceived after ART.

27 Limitations, reasons for caution: Imprinting disorders are rare events and our results are based on few ART children with imprinting disorders. The etiology is complex and only partly clarified, and the clinical diagnoses challenged by a broad phenotypic spectrum.

Wider implications of the findings: In the existing studies results on the risk of imprinting disorders in children conceived after ART are ambiguous. This study adds that the risk of imprinting disorders in ART children is very small and perhaps restricted to Beckwith-Wiedemann syndrome

34 Study funding/competing interest(s): This work was supported by the Nordic Trial Alliance: a pilot project jointly funded by the Nordic Council of Ministers and NordForsk [grant number 71450], the Nordic Federation of Obstetrics and Gynecology [grant numbers NF13041, NF15058, NF16026

37 and NF17043], and the Interreg Öresund-Kattegat-Skagerak European Regional Development 38 Fund (ReproUnion project). 


\section{Introduction}

Since the early days of assisted reproductive technology (ART), concern has prevailed, whether these techniques may influence the health of the offspring. Most published studies on child outcomes have been reassuring, although the risks of preterm birth and congenital malformations are moderately increased after ART (Pandey et al. 2012; Hansen et al. 2013). Conflicting results have emerged on the risk of imprinting disorders, which are characterized by molecular changes affecting imprinted chromosomal regions or genes that are expressed in a parent-of-origin specific manner (Doornbos et al. 2007; Gold et al. 2014; Lazaraviciute et al. 2014; Eggermann et al. 2015). Since methylation takes place during the preimplantation stages of embryonic development, where the embryo is handled in-vitro and cultured for up to six days in culture medias, ART may disturb the DNA methylation, resulting in imprinting errors. Furthermore, inherited epigenetic defects in the gametes may be more frequent in infertile men and women, causing an underlying increased risk of imprinting disorders, with or without ART (Niemitz et Feinberg 2004). Ludwig et al. (2005) showed that untreated couples with a time-to-pregnancy of more than two years had an increased risk of imprinting disorders, although they were not able to determine if the gametes, the embryo culture or the embryo manipulation were associated with the increased epigenetic instability.

The mechanisms behind imprinting disorders are difficult to assess, firstly due to the rarity of these disorders, as each disorder affects only 1 to 10 per 100000 newborns. Secondly, because these disorders may be the result of not only imprinting mechanisms, but also more classical genetic point mutations or micro deletions, conditions not expected to be influenced by in vitro techniques. Thirdly because the phenotype for each of these conditions has a relatively wide clinical spectrum, and therefore the specific diagnosis is often not made until several years after birth. Fourth, the cytogenetic techniques necessary to establish the exact mechanism behind each case have developed rapidly over the latest two decades, why an increasingly higher percentage of children with these disorders now get diagnosed. And finally, there is far from consensus on which disorders should be classified as imprinting disorders. The aim of this study was to assess the 
prevalence of Prader-Willi syndrome, Silver-Russell syndrome, Beckwith-Wiedemann syndrome and Angelman syndrome in children born after ART compared with children born after natural conception (NC).

\section{Materials and Methods}

This cohort comprised all live-born children born in Denmark during the period 1994 to 2014 and in Finland between 1990 and 2014. In total, 74637 ART children (singletons, $n=53$ 045; twins, $n=21$ 592) and 2775542 NC children (singletons, $n=2701$ 302; twins, $n=74$ 240) were included in the study. All triplets and quadruplets were excluded, but among them no children were diagnosed with imprinting disorders. Children conceived after medically assisted reproduction without in-vitro techniques herein ovarian stimulation or ovulation induction and inseminations were included in the control group of NC children. All data were collected from the relevant national health registries in Denmark and Finland. In Denmark, the $10^{\text {th }}$ version of International Statistical Classification of Diseases and Related Health Problems (ICD-10) was used throughout the study period. In Finland the ICD-9 version was used until 1995 and the ICD-10 version since 1996. The Finnish Register on Congenital Malformations have an additional text following the diagnosis code specifying the syndrome. In Denmark detailed information on the ART procedures was available from the national ART registry, whereas in Finland, information on use of ART or not, was the only available in the Finnish Medical Birth Registry and differentiation between the different ART methods not possible.

\section{Statistical analyses}

We described the characteristics of the mothers of children with and without imprinting disorders, born after ART and NC, respectively. Normally distributed quantitative data was summarized by means and standard deviations (SD) and compared using the two-sample t-test. Non-normally distributed quantitative data was summarized in median and quantiles and compared using the Mann-Whitney U-test. Categorial data was summarized in numbers and percentages and compared using Fishers exact test. The odds ratios (OR) of having one of the four imprinting disorders were calculated with 95\% confidence intervals. Multiple logistic regression analyses were 
used to adjust for maternal age, parity (nulliparous vs. multiparous), year of birth, child's sex, plurality, body mass index (BMI), smoking, and country.

\section{Ethical approval}

In Denmark and Finland, ethical approval is not required for scientific projects solely based on registry data.

\section{Results}

\section{Demographics}

The mothers of children diagnosed with an imprinting disorder were slightly older than mothers of children without imprinting disorders, both in the ART and NC group, but only statistically significant in the NC group (Table I). The prevalence of imprinting disorders did not differ significantly between boys and girls, although the figures were higher for boys among both ART and NC children (Table I). The median follow-up time was 8 years and 9 months for ART children and 11 years and 9 months for NC children. The median age at time of diagnosis was 11 months (interquartile range 2-23 months) for ART children and 30 months (interquartile range 6-69 months) for NC children, $p=0.20$.

\section{Imprinting disorders}

We identified 388 children diagnosed with the four imprinting disorders: Prader-Willi syndrome; Silver-Russell syndrome; Beckwith-Wiedemann syndrome and Angelman syndrome in Denmark and Finland during the study period. Sixteen of these children were conceived after ART (Table II). The prevalence of imprinting disorders was 21.4 per 100000 born in the ART group and 13.4 per 100000 in the NC group. The overall odds ratio (OR) of imprinting disorders after ART was 1.60 [95\%confidence interval (Cl) 0.97-2.65] (Table II). After adjusting for maternal age, parity (nulliparous vs. multiparous), year of birth, child's sex, smoking, BMI, and country, the adjusted odds ratio (AOR) for imprinting disorders among ART children was 1.35 [95\% Cl 0.80-2.29]. When investigating the four imprinting disorders separately, we found an increased odds ratio in children 
118

conceived after ART only for Beckwith-Wiedemann syndrome; OR 3.07 [95\%Cl 1.49-6.31]. This increased risk persisted after adjustment for potential confounders, AOR 2.84 [95\%Cl 1.34-6.01]. We found no significant differences between children conceived after ART and NC for Prader-Willi syndrome, Silver-Russell syndrome and Angelman syndrome. Among the nine Danish ART children diagnosed with an imprinting disorder, three children were conceived after IVF ( $n=24760)$ and six children after ICSI $(n=15517)$. None of the children were conceived after transfer of a frozen-thawed embryo.

\section{Discussion}

In this cohort study of all children born in Denmark and Finland over 25 years, the overall risk of the four imprinting disorders together was not increased. However, we found a significantly higher risk of Beckwith-Wiedemann syndrome, also in the adjusted analysis, AOR $2.84[95 \% \mathrm{Cl} 1.34-$ 6.01]. The increased risk of Beckwith-Wiedemann syndrome after ART is in line with several other studies demonstrating a potential association between ART and Beckwith-Wiedemann syndrome (Halliday et al. 2004; Lim et al. 2009; Mussa et al. 2017; Johnson et al. 2018). However, in our cohort, we were not able to demonstrate a potential association between ART and Prader-Willi syndrome, Silver-Russell syndrome and Angelman syndrome, as suggested by others (Cortessi et al. 2018; Hattori et al. 2019).

Imprinting is an epigenetic phenomenon restricting gene expression to one parental allele, while the other allele is inactivated (White et al. 2015). Epigenetic modifications are an important way of controlling gene activity, without altering the DNA sequence, and it is recognized that epigenetic alterations may increase the risk of various diseases later in life, such as diabetes, hypertension, cardiovascular diseases, as well as cancer (Bateson et al. 2004; Niemitz \& Feinberg 2004). The genome undergoes several phases of epigenetic programming during gametogenesis and early embryo development, coinciding with ART (Butler et al. 2009). A common process for controlling gene activity is methylation, often causing inactivation of the gene, and a high frequency of imprinted methylation errors in human preimplantation embryos has been demonstrated (White et 
al. 2015). Imprinting disorders are a group of congenital disorders with common underlying epigenetic etiologies, where alterations affecting imprinting genes or chromosomal regions result in clinical features affecting growth, development and metabolism. Imprinting disorders related to ART might take place just after fertilization at a time, where the epigenome could be most vulnerable, and a recent meta-analysis has suggested a positive association between ART and Prader-Willi syndrome, Silver-Russell syndrome, Beckwith-Wiedemann syndrome and Angelman syndrome (Cortessi et al. 2018). Almost all imprinting disorders are diagnosed in early childhood, although the clinical diagnosis can be delayed due to a broad phenotypic spectrum. Studies on mouse embryos have shown combined superovulation and embryo culture resulting in increased disruption of genomic imprinting (Market-Velker et al., 2010). The four imprinting disorders investigated in this study originate from different genetic modifications. If some imprinting disorders are more associated with ART than others, this suggests that some loci may be more vulnerable to external events, and the potential effect of ART procedures than others. The heterogeneity of the four imprinting disorders might be the explanation to why, we do not necessarily find a consistent increase in risk of imprinting disorders after ART. Furthermore, not all imprinting disorders are caused by methylation errors. For Beckwith-Wiedemann syndrome, uniparental disomy might be responsible for up to $20 \%$ of cases (Henry et al. 1991). Although based on only nine cases of ART children with imprinting disorders, we found a threefold of children conceived after ICSI versus IVF. Numbers are too small to draw any conclusions, but future studies should investigate this further. New ART techniques are continuously being developed and implemented, among others extended embryo culture from cleavage to blastocyst stage thus keeping the embryos 2-4 days more in invitro culture. Concomitantly vitrification has quickly overtaken slow-freezing for cryopreservation of surplus embryos. Studies have shown that children born after cryopreservation of embryos have an altered birthweight profile with a higher proportion of children being born large for gestational age (LGA), which may be caused by epigenetic modifications (Henningsen et al. 2011; Nelissen et al. 2012; Wennerholm et al. 2013). However, none of the Danish ART children with imprinting disorders were conceived after replacement of a frozen-thawed embryo. Hence, if an epigenetic 
171

172

173

174

175

176

177

178

179

modification causes LGA babies, it could be different from those potentially associated with the four imprinting disorders investigated in this study.

Ever since IVF was introduced, continuous attention has been on the outcome and health of ART children, but due to the rarity and heterogenicity of imprinting disorders, the field has been difficult to investigate. An early national Danish register study from our group could not demonstrate an increased risk of imprinting disorders (Lidegaard et al. 2005). Several studies have suggested an association between ART and Beckwith-Wiedemann syndrome (DeBaun et al. 2003; Gicquel et al. 2003; Maher et al. 2003; Halliday et al. 2004; Sutcliffe et al. 2006; Hiura et al. 2012; Mussa et al. 2017; Johnson et al. 2018).

The effects of both subfertility and ART on epigenetic gene regulation is unquestionably complex. Studies examining DNA methylation in children with imprinting disorders have not been able to identify specific changes in DNA methylation in selected genes, although some studies find that the methylation error rates are significantly higher in children conceived after ART (Lim et al. 2009; Lazaraviciute et al. 2014; Hattori et al. 2019). Advanced parental age is known to predispose to genetic errors causing also imprinting disorders. When Hattori et al. (2019) stratified their analyses on maternal age above or below 37 years for children with Prader-Willi syndrome, they found the rate of methylation errors to be significantly increased in ART compared with NC children, also in mothers less than 37 years. This indicates that not only maternal age, but also ART may affect DNA methylation, and potentially the risk of imprinting disorders (Cortessi et al. 2018; Hattori et al., 2019).

The strength in this register-based investigation of imprinting disorders is two large Nordic national datasets with high coverage and validity. The main weakness is the few imprinting disorders in the ART group, limiting the power of our study. A further weakness of this study is that the ICD-10 codes are not specific for the mechanisms behind these syndromes. In our analyses, we chose to use logistic regression instead of survival analyses, as we do not consider the aspect of age at diagnosis crucial, when investigating the risk of disorders that are present already at birth, and 
diagnosed during the first years of life for both ART and NC children The difference in length of follow-up between the two groups is therefore not expected to influence our results. If anything, adjustment for length of follow-up would overestimate the risk of imprinting disorders in the ART group a little. Nevertheless, we found a lower age at diagnosis in ART children compared to NC children. A longer follow-up is needed to determine whether this results from a shorter follow-up for the ART children in this cohort or from a shift in time of diagnosis, for example due to increased parental awareness. In the latter situation, survival analysis might overestimate the risk of imprinting disorders in ART.

Due to lack of power, we were not able to analyze the frequency of imprinting disorders in children conceived after culturing of the embryo to the blastocysts stage. However, White et al. (2015), who investigated the occurrence of imprinted methylation errors in human preimplantation embryos found evidence that methylation errors derive as early as the 6-8 cell stage, and that extended culture time to the blastocysts stage did not increase the risk of imprinting errors.

In conclusion, this large-scale cohort study, demonstrated no overall increased risk of imprinting disorders in children conceived after ART, but only an increased risk of Beckwith-Wiedemann syndrome. If only some imprinting disorders are associated with ART, this suggests that some loci may be more vulnerable to external events, and the potential effect of ART procedures, than others.

\section{Author's roles}

All authors planned the study and discussed the results. S.R., A.L.S., A.A.H., M.G. and S.O. fitted and merged data. A.A.H. performed the analyses and drafted the manuscript. J.L.F. contributed to the data analyses and interpretation. All authors were involved in finalising the manuscript and approved the final version. The authors agreed upon the listing of authors.

\section{Funding}


221 This work was supported by the Nordic Trial Alliance: a pilot project jointly funded by the Nordic

222 Council of Ministers and NordForsk [grant number 71450], the Nordic Federation of Obstetrics and 223 Gynecology [grant numbers NF13041, NF15058, NF16026 and NF17043], and the Interreg 224 Öresund-Kattegat-Skagerrak European Regional Development Fund (ReproUnion project).

225 Conflict of interest

226 No conflict of interest was reported. 


\section{References}

1. Bateson P, Barker D, Clutton-Brock T, Deb D, D'Udine B, Foley RA, Gluckman P, Godfrey K, Kirkwood T, Lahr MM et al. Developmental plasticity and human health. Nature 2004; 430: $419-421$

2. Butler MG. Genomic imprinting disorders in humans: a mini-review. J assist Reprod Genet 2009; 26: 477-486

3. Cortessis VK, Azadian M, Buxbaum J, Sanogo F, Song AY, Sriprasert I, Wei PC, Yu J, Chung K, Siegmund KD. Comprehensive meta-analysis reveals association between multiple imprinting disorders and conception by assisted reproductive technology. J Assist Reprod Genet. 2018; 35: 943-952

4. DeBaun MR, Niemetz EL, Feinberg AP. Association of in vitro fertilization with BeckwithWiedemann syndrome and epigenetic alterations of LIT1 and H19. Am J Hum Genet. 2003; 72:156-160.

5. Doornbos ME, Maas SM, McDonnell J, Vermeiden JP, Hennekam RC. Infertility, assisted reproduction technologies and imprinting disturbances: a Dutch study. Hum Reprod. 2007; 22: $2476-2480$

6. Eggermann T, Perez de Nanclares G, Maher ER, Temple IK, Tümer Z, Monk D, Mackay DJG, Grønskov K, Riccio A, Linglart A et al. Imprinting disorders: a group of congenital disorders with overlapping patterns of molecular changes affecting imprinted loci. Clin Epigenetics 2015; 7: 123

7. Gicquel C, Gastron V, Mandelbaum J, Siffroi JP, Flahault A, Le Bouc Y. In vitro fertilization may increase the risk of Beckwith-Wiedemann syndrome related to the abnormal imprinting of the KCN1OT. Am J Hum Genet. 2003; 72: 1338-1341

8. Gold JA, Ruth C, Osann K, Flodman P, Mcmanus B, Lee HS, Donkervoort S, Khare M, Roof E, Dykens E et al. Frequency of Prader-Willi syndrome in births conceived via assisted reproductive technology. Genet Med. 2014; 16: 164-169. 
9. Hansen M, Kurinczuk JJ, Milne E, Klerk N, Bower C. Assisted reproductive technology and birth defects: a systematic review and meta-analysis. Hum Reprod Update 2013; 19: 330353

10. Halliday J, Oke K, Breheny S, Algar E, Amor D. Beckwith-Wiedemann syndrome and IVF: a case-control study. Am J Hum Genet 2004; 75: 526-528

11. Hattori H, Hiura H, Kitamura A, Miyauchi N, Kobayashi N, Takahashi S, Okae H, Kyono K, Kagami M, Ogata T et al. Association of four imprinting disorders and ART. Clinical Epigenetics 2019; 11: 21

12. Henningen AA, Pinborg A, Lidegaard O, Vestergaard C, Forman JL, Nyboe Andersen A. Perinatal outcome of singleton siblings born after assisted reproductive technology and spontaneous conception: Danish national sibling-cohort study. Fertil Steril; 95: 959-963

13. Henry I, Bonaiti-Pellié C, Chehensse V, Beljord C, Schwartz C, Utermann G, Junien C. Uniparental paternal disomy in a genetic cancer-predisposing syndrome. Nature 1991; 351: $665-667$

14. Hiura H, Okae H, Miyauchi N, Sato F, Sato A, Van De Pette M, John RM, Kagami M, Nakai $\mathrm{K}$, Soejima $\mathrm{H}$ et al. Characterization of DNA methylation errors in patients with imprinting disorders conceived by assisted reproduction technologies. Hum Reprod. 2012; 27 : 2541 2548

15. Johnson JP, Beischel L, Schwanke C, Styren K, Crunk K, Schoof J, Elias AF. Overrepresentation of pregnancies conceived by artificial reproductive technology in prenatally identified fetuses with Beckwith-Wiedemann syndrome. J Assist Reprod Genet 2018; 35: 985-992

16. Lazaraviciute G, Kauser M, Bhattacharya S, Haggarty P, Bhattacharya S. A systematic review and meta-analysis of DNA methylation levels and imprinting disorders in children conceived by IVF/ICSI compared with children conceived spontaneously. Hum Reprod Update 2014; 20: 840-852 
17. Lidegaard O, Pinborg A, Andersen AN. Imprinting diseases and IVF: Danish National IVF cohort study. Hum Reprod 2005; 20: 950-954

18. Lim D, Bowdin SC, Tee L, Kirby GA, Blair E, Fryer A, Lam W, Oley C, Cole T, Brueton LA et al. Clinical and molecular genetic features of Beckwith-Wiedemann syndrome associated with assisted reproductive technologies. Hum Reprod 2009; 24: 741-747

19. Ludwig M, Katalinic A, GroB S, Sutcliffe A, Varon R, Horsthemke B. Increased prevalence of imprinting defects in patients with Angelman syndrome born to subfertile couples. J Med Genet 2005; 42: 289-291

20. Maher ER, Brueton LA, Bowdin SC, Luharia, Cooper W, Cole TR, Macdonald F, Sampson JR, Barratt CL, Reik W et al. Beckwith-Wiedemann syndrome and assisted reproductive technology (ART). J Med Genet. 2003; 40:62-64.

21. Market-Velker BA, Zhnag L, Magri LS, Bonvissuto AC, Mann MR. Dual effects on superovulation: loss of maternal and paternal imprinted methylation in a dose-dependent manner. Hum Mol Genet 2010; 19: 36-51

22. Mussa A, Molinatto C, Cerrato F, Palumbo O, Carella M, Baldassare G, Carli D, Peris C, Riccio A, Ferrero GB. Assisted reproductive techniques and risk of Beckwith-Wiedemann syndrome. Pediatrics 2017; 140: e20164311

23. Nelissen EC, Van Montfoort AP, Coonen E, Derhaag JG, Geraedts JP, Smits LJ, Land JA, Evers JL, Dumoulin JC. Further evidence that culture media affect perinatal outcome: findings after transfer of fresh and cryopreserved embryos. Human Reprod 2012; 27: 19661976

24. Niemitz EL et Feinberg AP. Epigenetics and assisted reproductive technology: a call for investigation. Am J Hum Genet 2004; 74: 599-609

25. Pandey S, Shetty A, Hamilton M, Bhattacharya S, Maheshwari A. Obstetric and perinatal outcomes in singleton pregnancies resulting from IVF/ICSI: a systematic review and metaanalysis. Hum Reprod Update 2012; 18: 485-503 
26. Sutcliffe AG, Peters CJ, Bowdin S, Temple K, Reardon W, Wilson L, Clayton-Smith J, Brueton LA, Bannister W, Maher ER. Assisted reproductive therapies and imprinting disorders, - a preliminary British survey. Hum Reprod. 2006; 21: 1009-1011

27. Wennerholm UB, Henningsen AA, Romundstad LB, Bergh C, Pinborg A, Skjaerven R, Forman J, Gissler M, Nygren KG, Tiitinen A. Perinatal outcomes of children born after frozen-thawed embryo transfer: a Nordic cohort study from the CoNARTaS group. Hum Reprod 2013; 28: 2545-2553

28. White CR, Denomme MM, Tekpetey FR, Feyles V, Power SGA, Mann MRW. High frequency of imprinted methylation errors in human preimplantation embryos. Sci Rep.5, 17311; doi: 10.1038/srep17311 (2015) 
Table I Descriptive data of children with and without imprinting disorders, and their mothers.

\begin{tabular}{|c|c|c|c|c|c|c|c|}
\hline & \multicolumn{3}{|c|}{$\begin{array}{l}\text { Assisted reproductive technology } \\
\text { (ART) }\end{array}$} & \multicolumn{3}{|c|}{$\begin{array}{l}\text { Natural conception } \\
\text { (NC) }\end{array}$} & \multirow[b]{2}{*}{$\begin{array}{l}\text { ART vs } \\
\text { NC }\end{array}$} \\
\hline & $\begin{array}{l}\text { Imprinting } \\
\text { disorder }\end{array}$ & $\begin{array}{l}\text { No imprinting } \\
\text { disorder }\end{array}$ & & $\begin{array}{l}\text { Imprinting } \\
\text { disorder }\end{array}$ & $\begin{array}{l}\text { No imprinting } \\
\text { disorder }\end{array}$ & & \\
\hline & $\mathrm{n}=16$ & $n=74621$ & $\mathrm{P}$ & $n=372$ & $n=2775239$ & $p$ & $p$ \\
\hline $\begin{array}{l}\text { Maternal age } \\
(\text { mean } \pm S D)\end{array}$ & $35.8 \pm 4.2$ & $33.7 \pm 4.3$ & 0.06 & $31.1 \pm 5.4$ & $30.0 \pm 5.1$ & $<0.001$ & \\
\hline Smokers (\%) & 0.0 & 8.0 & 0.25 & 17.7 & 16.1 & 0.43 & \\
\hline BMI>30 (\%) & 0.0 & 5.7 & 0.32 & 6.7 & 5.3 & 0.23 & \\
\hline Nulliparous (\%) & 62.5 & 67.5 & 0.67 & 41.2 & 41.6 & 0.87 & \\
\hline Boys (\%) & 68.8 & 50.9 & 0.15 & 53.9 & 51.2 & 0.30 & \\
\hline \multicolumn{8}{|l|}{$\begin{array}{l}\text { Age at } \\
\text { diagnosis }\end{array}$} \\
\hline $\begin{array}{l}\text { (median, } \\
\text { interquartile } \\
\text { range, months) }\end{array}$ & $11[2-23]$ & & & 30 [6-69] & & & 0.20 \\
\hline \multicolumn{8}{|l|}{ Follow-up } \\
\hline $\begin{array}{l}\text { (median, } \\
\text { interquartile } \\
\text { range, years) }\end{array}$ & $\begin{array}{c}7.0 \\
{[3.2-10.9]^{1}}\end{array}$ & $\begin{array}{c}8.9 \\
{[4.1-14.0]^{2}}\end{array}$ & & $\begin{array}{c}10.7 \\
{[6.0-16.9]^{1}}\end{array}$ & $\begin{array}{c}11.8 \\
{[5.9-17.6]^{2}}\end{array}$ & & $0.02^{1} ;<0.001^{2}$ \\
\hline \multicolumn{8}{|l|}{ Follow-up } \\
\hline $\begin{array}{l}\text { (median, } \\
\text { interquartile } \\
\text { range, years) }\end{array}$ & $8.8[4$ & $.1-14.0]$ & & 11.8 & 5.9-17.7] & & $<0.001$ \\
\hline
\end{tabular}




\section{Table II.}

Risk of Prader-Willi syndrome, Silver-Russel syndrome, Beckwith-Wiedemann syndrome and Angelman syndrome in Finnish and Danish children born from 1990/1994 to 2014

\begin{tabular}{lccccc}
\hline & $\begin{array}{c}\text { Prader-Willi } \\
\text { syndrome }\end{array}$ & $\begin{array}{c}\text { Silver-Russell } \\
\text { syndrome }\end{array}$ & $\begin{array}{c}\text { Beckwith- } \\
\text { Wiedemann } \\
\text { syndrome }\end{array}$ & $\begin{array}{c}\text { Angelman } \\
\text { syndrome }\end{array}$ & $\begin{array}{c}\text { All four } \\
\text { imprinting } \\
\text { disorders }\end{array}$ \\
\hline \multicolumn{7}{c}{ Assisted reproductive technology (ART) } \\
\hline Children born & 74621 & 74621 & 74621 & 74621 & 74621 \\
Imprinting & 5 & $<3^{\#}$ & 8 & $<3^{\#}$ & 16 \\
Rate/10 000 & 0.67 & 0.27 & 1.07 & 0.27 & 2.14 \\
\hline \multicolumn{7}{c}{ Natural conception (NC) } \\
\hline Children born & 2775239 & 2775239 & 2775239 & 2775239 & 2775239 \\
Imprinting & 138 & 67 & 97 & 70 & 372 \\
Rate/10 000 & 0.50 & 0.24 & 0.35 & 0.25 & 1.34 \\
\hline \multicolumn{7}{c}{ ART versus NC } \\
\hline Crude odds ratio & 1.35 & 1.11 & 3.07 & 0.53 & 1.60 \\
[95\%Cl] & {$[0.55-3.29]$} & {$[0.27-4.53]$} & {$[1.49-6.31]$} & {$[0.07-3.82]$} & {$[0.97-2.65]$} \\
Adj.* odds ratio & 1.03 & 0.82 & 2.84 & 0.51 & 1.35 \\
[95\%Cl] & {$[0.37-2.84]$} & {$[0.20-3.43]$} & {$[1.34-6.01]$} & {$[0.07-3.74]$} & {$[0.80-2.29]$} \\
\hline
\end{tabular}

\#due to Danish law on health data, we are not allowed to show data on groups of less than three individuals *adjustments were made for maternal age, parity (nulliparous vs. multiparous), year of birth, child's sex, body mass index (BMI), smoking and country 
Table III.

National cohorts and case-control studies investigating the prevalence of Prader-Willi syndrome, Silver-Russell syndrome, Beckwith-Wiedemann syndrome and Angelman syndrome

\begin{tabular}{|c|c|c|c|c|c|c|}
\hline & \multicolumn{6}{|c|}{ Prader-Willi syndrome (PWS) } \\
\hline & \multicolumn{2}{|c|}{ ART } & \multicolumn{2}{|c|}{ NC } & \multirow{2}{*}{$\begin{array}{c}\text { Prevalence } \\
/ 100000\end{array}$} & \multirow{2}{*}{$\begin{array}{c}\text { Ratio } \\
\text { RR* }^{*}[95 \% \mathrm{Cl}]\end{array}$} \\
\hline & PWS & total & PWS & total & & \\
\hline Källén, 2005 (S) & 1 & 16280 & 0 & 2023663 & 0.05 & - \\
\hline Lidegaard, 2005 (DK) & 0 & 6052 & 3 & 436297 & 0.7 & 0 \\
\hline Sutcliffe, 2006 (UK) & 2 & 68566 & 161 & 8327061 & 1.9 & $1.5[0.4-6.1]$ \\
\hline Doornboos, 2007 (NL) & 2 & 83818 & 84 & 3954461 & 2.1 & $1.1[0.3-4.6]$ \\
\hline Hiura, 2012 (Japan) & 4 & 10524 & 261 & 1123610 & 23.4 & $1.6[0.6-4.4]$ \\
\hline Gold, 2014 (US) & 20 & 25015 & 1864 & 3960909 & 47.3 & $1.7[1.1-2.6]$ \\
\hline Hattori, 2019 (Japan) & 24 & $1.3 \%$ & 520 & $98.7 \%$ & $\mathrm{Na}^{* *}$ & $3.4\left[\mathrm{na}^{* *}\right]$ \\
\hline \multirow[t]{4}{*}{ Henningsen, 2019 (DK) } & 5 & 74621 & 138 & 2775239 & 5.0 & $1.0[0.4-2.8]$ \\
\hline & \multicolumn{6}{|c|}{ Silver-Russell syndrome (SRS) } \\
\hline & \multicolumn{2}{|c|}{ ART } & \multicolumn{2}{|c|}{ NC } & Prevalence & Ratio \\
\hline & SRS & total & SRS & total & $/ 100000$ & $\mathrm{RR}^{*}[95 \% \mathrm{Cl}]$ \\
\hline Källén, 2005 (S) & 1 & 16280 & 0 & 2023663 & 0.05 & - \\
\hline Lidegaard, 2005 (DK) & 0 & 6052 & 2 & 436297 & 0.5 & 0 \\
\hline Hiura, 2012 (Japan) & 4 & 10524 & 42 & 1123610 & 4.0 & $10.2[3.6-28.4]$ \\
\hline Hattori, 2019 (Japan) & 8 & $1.3 \%$ & 67 & $98.7 \%$ & $\mathrm{Na**}$ & $8.9[\mathrm{na**}]$ \\
\hline \multirow[t]{4}{*}{ Henningsen, 2019 (DK) } & 2 & 74621 & 67 & 2775239 & 2.4 & $0.8[0.2-3.4]$ \\
\hline & \multicolumn{6}{|c|}{ Beckwith-Wiedemann syndrome (BWS) } \\
\hline & \multicolumn{2}{|c|}{ ART } & \multicolumn{2}{|c|}{ NC } & Prevalence & Ratio \\
\hline & BWS & total & BWS & total & $/ 100000$ & RR* $[95 \% \mathrm{Cl}]$ \\
\hline DeBaun, 2003 (US) & 3 & 30285 & 62 & 3920132 & 1.6 & $6.3[2.0-20.0]$ \\
\hline Gicquel, 2003 (F) & 6 & 9930 & 143 & 760070 & 19.4 & $3.2[1.4-7.3]$ \\
\hline Maher, 2003 (UK) & 6 & 43074 & 143 & 4277408 & 3.4 & $4.2[1.8-9.4]$ \\
\hline Halliday, 2004 (Aus) & 4 & 14894 & 33 & 1301606 & 2.8 & $10.6[3.8-29.9]$ \\
\hline Sutcliffe, 2006 (UK) & 6 & 68566 & 73 & 8327061 & 0.9 & $10.0[4.3-22.9]$ \\
\hline Doornboos, 2007 (NL) & 4 & 83818 & 69 & 3954461 & 1.8 & $2.7[1.0-7.5]$ \\
\hline Hiura, 2012 (Japan) & 6 & 10524 & 70 & 1123610 & 6.7 & $9.2[4.0-21.1]$ \\
\hline Mussa 2017 (Italy) & 7 & 7884 & 31 & 371988 & 10.0 & $10.7[4.7-24.2]$ \\
\hline Hattori, 2019 (Japan) & 7 & $1.3 \%$ & 117 & $98.7 \%$ & $\mathrm{Na} * *$ & $4.5\left[\mathrm{na}^{* *}\right]$ \\
\hline \multirow[t]{4}{*}{ Henningsen, 2019 (DK) } & 8 & 74621 & 97 & 2775239 & 3.7 & $2.8[1.3-6.0]$ \\
\hline & \multicolumn{6}{|c|}{ Angelman syndrome (AS) } \\
\hline & \multicolumn{2}{|c|}{ ART } & \multicolumn{2}{|c|}{ NC } & Prevalence & Ratio \\
\hline & AS & total & AS & total & $/ 100000$ & $\mathrm{RR}^{*}[95 \% \mathrm{Cl}]$ \\
\hline Sutcliffe, 2006 (UK) & 1 & 68566 & 74 & 8327061 & 0.89 & $1.6[0.2-11.8]$ \\
\hline Doornboos, 2007 (NL) & 0 & 83818 & 63 & 3954461 & 1.6 & 0 \\
\hline Hiura, 2012 (Japan) & 2 & 10524 & 123 & 1123610 & 11.0 & $1.7[0.4-7.0]$ \\
\hline Hattori, 2019 (Japan) & 4 & $1.3 \%$ & 227 & $98.7 \%$ & $\mathrm{Na} * *$ & $1.3\left[\right.$ na**$\left.^{*}\right]$ \\
\hline Henningsen, 2019 (DK) & 1 & 74621 & 70 & 2775239 & 2.5 & $0.5[0.1-3.7]$ \\
\hline
\end{tabular}

$R R^{*}=$ rate ratio; $\mathrm{Na}^{* *}=$ not available 